\title{
ERRATUM
}

\section{Erratum to: Effect of Patient- and Medication-Related Factors on Inpatient Medication Reconciliation Errors}

\author{
Amanda H. Salanitro, MD, MS, MSPH ${ }^{1,2}$, Chandra Y. Osborn, $P h D, M P H^{3,4}$, \\ Jeffrey L. Schnipper, MD, MPH ${ }^{5,6,7}$, Christianne L. Roumie, MD, $M P H^{1,3,4,8}$, \\ Stephanie Labonville, PharmD ${ }^{9}$, Daniel C. Johnson, PharmD, BCPS ${ }^{10}$, Erin Neal, PharmD, BCPS ${ }^{10}$, \\ Courtney Cawthon, $\mathrm{MPH}^{4}$, Alexandra Businger, BA ${ }^{5}$, Anuj K. Dalal, MD ${ }^{5,6,7}$, \\ and Sunil Kripalani, MD, MSc $c^{2,3,4}$
}

${ }^{2}$ Department of Veterans Affairs, Tennessee Valley Healthcare System Geriatric Research Education and Clinical Center (GRECC), Nashville, TN, USA; 'Section of Hospital Medicine, Vanderbilt University, GRECC Room A-414, 1310 24th Avenue South, Nashville, TN 372 12, USA; ${ }^{3}$ Division of General Internal Medicine and Public Health, Vanderbilt University, Nashville, TN, USA; ${ }^{4}$ Center for Health Services Research, Vanderbilt University, Nashville, TN, USA; ${ }^{5}$ Division of General Medicine and Primary Care, Brigham and Women's Hospital, Boston, MA, USA; ${ }^{6}$ BWH Hospitalist Service, Brigham and Women's Hospital, Boston, MA, USA; 7 Harvard Medical School, Boston, MA, USA; ${ }^{8}$ Department of Pediatrics, Vanderbilt University, Nashville, TN, USA; ${ }^{9}$ Department of Pharmacy Services, Brigham and Women's Hospital, Boston, MA, USA; ${ }^{10}$ Department of Pharmaceutical Services, Vanderbilt University Medical Center, Nashville, TN, USA.

Erratum to: J Gen Intern Med

DOI: $10.1007 / \mathbf{s} 11606-012-2003-y$

$\mathrm{O}$ n page 6 of the original publication, in the first full paragraph, "an additional 73 patients" should read simply "73 patients," "another 38 patients" should read simply "38 patients," and "an additional 126 patients" should read simply "126 patients."

Corresponding Author: Amanda H. Salanitro, MD, MS, MSPH; Section of Hospital Medicine, Vanderbilt University, GRECC Room A-414, 1310 24th Avenue South, Nashville, TN 37212, USA (e-mail: Amanda.Salanitro@Vanderbilt.Edu).

The online version of the original article can be found at http:// dx.doi.org/10.1007/s11606-012-2003-y.

Published online July 27, 2012 